\title{
Rancang Bangun Alat Ukur Kualitas Jaringan Berbasis Raspberry Pi 3 Model B
}

\author{
Joshua F Sudarsono $^{1}$, Gede Sukadarmika ${ }^{2}$, Linawati ${ }^{3}$ \\ [Submission: 31-05-2020, Accepted: 05-02-2021]
}

\begin{abstract}
The Internet has become a necessity for modern society in carrying out its various activities today. The rapid increase in Internet users annually shows that people's need for the Internet is increasing. In Indonesia, Internet user growth is predicted to increase by 10.2 percent annually from 2018 to 2023 . However, the growth in the number of customers is often not followed by the ability of Internet providers to improve maintenance facilities to maintain the quality of service to their customers. One of the causes is the limitations of the device which is often an obstacle for technicians to do maintenance as soon as possible. This research aims to be able to design and build devices that can be applied as a means of measuring network quality more simply and economically so as to support the mobility of technicians to use and maintain their networks. The devices built on the study are based on the Raspberry Pi 3 Model B. Comparison of device performance measurement results such as battery life, ping, upload, and download rate between devices built with laptop usage gives almost the same results. This device has advantages on the side of smaller and lighter dimensions and a much more.
\end{abstract}

Intisari-Internet telah menjadi kebutuhan bagi masyarakat modern dalam melakukan berbagai aktifitasnya saat ini. Pengguna Internet yang meningkat sangat pesat di setiap tahun menunjukkan bahwa kebutuhan masyarakat terhadap Internet yang semakin tinggi. Di Indonesia pertumbuhan pengguna Internet diprediksi meningkat 10,2 persen setiap tahunnya dari tahun 2018 hingga 2023. Namun demikian, pertumbuhan jumlah pelanggan sering kali tidak diikuti dengan kemampuan provider Internet untuk meningkatkan fasilitas maintenance dan untuk menjaga kualitas layanan kepada pelanggannya. Salah satu penyebabnya adalah keterbatasan perangkat yang sering kali menjadi kendala bagi teknisi untuk mealakukan maintenance sesegera mungkin. Penelitian ini bertujuan untuk dapat merancang dan membangun perangkat yang dapat digunakan sebagai alat ukur kualitas jaringan yang lebih sederhana dan ekonomis sehingga mendukung mobilitas teknisi untuk membangun maupun maintenance jaringannya. Perangkat yang dibangun pada penelitian ini berbasis Raspberry Pi 3 Model B. Perbandingan hasil pengukuran performa perangkat antara lain daya tahan baterai, ping, upload dan download rate antara perangkat yang dibangun dengan penggunaan laptop memberikan hasil yang hampir sama. Perangkat yang dibangun ini memiliki keunggulan pada sisi dimensi yang lebih kecil dan ringan serta biaya yang jauh lebih ekonomis.

Kata Kunci- Internet, QoS, Speedtest, Raspberry Pi, Ookla, Maintenance, Provider, Perangkat

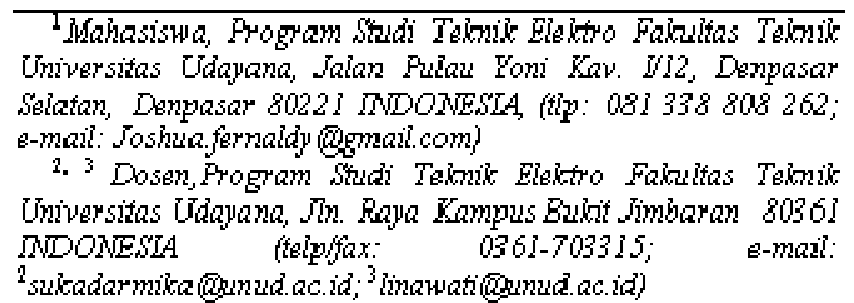

suadarmikanudacid inawatignudacid)

\section{PENDAHULUAN}

Internet merupakan jaringan komunikasi yang menyambungkan banyak perangkat elektronik dengan standar Transmission Control Protocol (TCP) atau Internet Protocol Suite (IP) yang dipakai secara global [1]. Internet telah menjadi kebutuhan bagi masyarakat modern saat ini. Pengguna Internet yang meningkat sangat pesat di setiap tahun menunjukkan bahwa kebutuhan masyarakat terhadap Internet yang semakin tinggi.

Berdasarkan data statistika di tahun 2019 menunjukkan pada tahun 2018 jumlah pengguna internet di Indonesia mencapai angka 95,2 juta, meningkat sebanyak 13,3\% dari tahun sebelumnya sebanyak 84 juta. Kemudian di tahun 2019 jumlah pengguna internet di proyeksikan akan mengalami peningkatan 12,6\% dari tahun 2018 menjadi 107,2 juta pengguna. Pengguna internet di Indonesia diprediksi akan semakin tumbuh dengan rata-rata peningkatan sebanyak $10,2 \%$ selama periode 2018-2023 [2].

Melihat pesatnya pertumbuhan pengguna internet di Indonesia, maka perusahaan penyedia layanan harus lebih memperhatikan kualitas layanan yang disebut Quality of Service (QoS) sebagai tolok ukur layanan yang baik. Quality of Service (QoS) itu sendiri merupakan kemampuan jaringan untuk menyediakan bandwidth, mengatasi jitter dan delay [3]. Kualitas jaringan sangatlah penting dikarenakan banyak hal yang bisa didapatkan melalui internet. Dalam menjaga kualitas layanan diperlukan pemeliharaan jaringan. Salah satu upaya pemeliharaan jaringan adalah dengan melakukan pengukuran kualitas jaringan terutama pada saat pemasangan jaringan baru.

Adapun beberapa penelitian yang pernah dilakukan untuk meningkatkan kualitas jaringan atau berkaitan dengan Quality of Service (QoS). Seperti peneletian yang dilakukan oleh Anrisam Gusnium Nasution tentang Perancangan Jaringan Fiber to The Home (FTTH) dengan Teknologi Gigabit Passive Optical Network (GPON) (Studi Kasus di Daerah Turangga Bandung). Penelitian ini bertujuan merancang jaringan optik FTTH dengan menggunakan teknologi GPON di daerah Turangga, Bandung [4].

Penelitian yang dilakukan oleh Dhian tentang Analisis Kualitas Jaringan Akses Indihome untuk Teknologi GPON dan MSAN di STO Darussalam. Penelitian ini membahas tentang layanan Indihome yang dimiliki PT Telkom Indonesia sebagai salah satu penyedia jasa layanan dan akses layanan IndiHome dapat digunakan untuk suara, data, dan video (triple play) [5].

Penelitian Haryanto tentang Peningkatan Kualitas Jaringan Komunikasi Sektor Industri dengan Intelligent

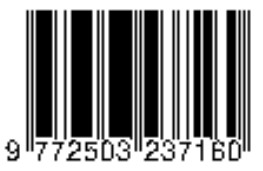


Network Sebagai Upaya Perluasan Daerah Pemasaran yang bertujuan untuk meningkatkan kualitas jaringan telekomunikasi dengan infrastruktur yang memadai dengan standar spesifikasi mobile system yang akan digunakan. Sehingga dapat meningkatkan perkembangan daerah dengan terjangkaunya komunikasi di daerah terisolasi dan memunculkan daerah-daerah sentra produksi di bidang industri [6].

Penelitian yang dilakukan oleh Wulandari tentang Analisis QoS (Quality of Service) pada Jaringan Internet (Studi Kasus: UPT Loka Uji Teknik Penambangan Jampang Kulon-Lipi). Penelitian ini bertujuan untuk menganalisa QoS dimana QoS didefinisikan sebagai ukuran seberapa baik jaringan dan upaya untuk mendefinisikan karakteristik dan sifat layanan [7].

Penelitian yang dilakukan oleh Wijatsongko tentang Sistem Pemantauan Ruangan dengan Server Raspberry Pi. Penelitian ini bertujuan untuk mengatasi masalah besarnya file yang membebani storage pada server, karena ukuran berkas video hasil rekaman akan sangat besar. Salah satu cara untuk mengatasi masalah tersebut adalah dengan membuat agar webcam hanya merekam pada saat-saat dibutuhkan saja [8].

Penelitian yang dilakukan oleh Kompyang Agus Subrata tentang Klasifikasi Penggunaan Protokol Komunikasi pada Trafik Jaringan Menggunakan Algoritma K-Nearest Neighbor. Penelitian ini bertujuan untuk mengklasifikasi pemberian prioritas QoS dengan menganalisa data trafik jaringan. Klasifikasi dilakukan menggunakan Algoritma K-Nearest Neighbor $(K-N N)$ dan aplikasi Wireshark untuk menangkap data trafik jaringan [9].

Penelitian yang dilakukan oleh Oka Widyantara tentang Analisa Horizontal Handover Terhadap QoS Layanan Streaming Multimedia E-Learning pada Jaringan WLAN 802.11. Penelitian ini bertujuan untuk menganalisis pengaruh handover yang diakibatkan karena pengguna internet selalu berpindah pindah tempat yang mempengaruhi Quality of Service di WLAN 802.11 terhadap streaming e-learning [10].

Penelitian yang dilakukan Nyoman Bernadus tentang Analisis Kinerja Jaringan Internet Menggunakan Metode Class Based Queueing (CBQ) di Universitas Dhyana Pura. Penelitian ini bertujuan untuk menganalisa Quality of Service dengan parameter-parameter throughput, delay, packet loss, jitter dan bandwidth menggunakan metode CBQ yang merupakan metode manajemen bandwidth [11].

Berdasarkan beberapa hasil survei di lapangan terdapat kendala bahwa peralatan yang dibawa oleh teknisi kurang praktis dalam artian terlalu besar, berat, dan sulit dibawa, sehingga diperlukan alternatif alat untuk mendukung mobilitas mereka di lapangan baik dalam dimensi dan berat. Saat ini provider layanan telekomunikasi, contohnya PT. Telekomunikasi Indonesia menggunakan perangkat laptop sebagai alat uji kualitas jaringannya. Pemanfaatan laptop sebagai perangkat disinyalir kurang praktis dan ekonomis untuk digunakan. Dengan demikian PT. Telekomunikasi Indonesia memiliki keterbatasan menyediakan perangkat yang dibawa oleh setiap teknisinya untuk melakukan pengukuran di lapangan.

Berdasarkan beberapa penelitian terkait dengan Quality of Service (QoS) dan survei di lapangan, pada penelitian ini penulis merancang dan membuat alat ukur kualitas jaringan yang dapat digunakan sebagai alternatif pengganti dari fungsi laptop. Perangkat yang dibuat berbasis Raspberry Pi dan hasil ukur dari perangkat yang dibuat akan dibandingkan dangan hasil ukur perangkat yang digunakan saat ini (laptop).

\section{TINJAUAN PUSTAKA}

Beberapa referensi yang bersesuaian dengan alat yang dibuat diuraikan pada bagian ini.

\section{A. Quality of Service (QoS)}

Quality of Service (QoS) merupakan sebuah arsitektur end-to-end dan bukan merupakan sebuah fitur yang dimiliki oleh jaringan. QoS suatu jaringan merujuk pada tingkat kecepatan dan kehandalan penyampaian berbagai jenis data di dalam suatu komunikasi. QoS menawarkan kemampuan untuk mendefinisikan atribut-atribut layanan yang disediakan, baik secara kualitatif maupun kuantitatif.

Dalam penggunaanya QoS memiliki beberapa manfaat, yaitu memberikan prioritas untuk aplikasi-aplikasi yang kritis pada jaringan, memaksimalkan penggunaan investasi jaringan yang sudah ada, meningkatkan performa untuk aplikasiaplikasi yang sensitif terhadap delay, seperti Voice dan Video, dan merespon terhadap adanya perubahan-perubahan pada aliran trafik di jaringan.

Beberapa Parameter QoS, yaitu:

\section{1) Bandwidth}

Bandwidth adalah luas atau lebar cakupan frekuensi yang digunakan oleh sinyal dalam medium transmisi. Bandwidth dapat juga dikatakan sebagai kecepatan transfer data (transfer rate) yaitu jumlah data yang dapat dibawa dari sebuah titik ke titik lain dalam jangka waktu tertentu (detik).

\section{2) Throughput}

Throughput adalah kecepatan (rate) transfer data efektif yang diukur dalam bps. Throughput merupakan jumlah total kedatangan paket yang sukses yang diamati pada destination selama interval waktu tertentu dibagi oleh durasi interval waktu tersebut. Throughput dirumuskan sebagai berikut:

$$
\text { Throughput: } \frac{\text { Paoket Received }(\mathrm{kB})}{\text { Time Transmitted (s) }}
$$

Berikut merupakan standar Throughput menurut TIPHON [12]:

TABEL 1

STANDAR THROUGHPUT

\begin{tabular}{|c|c|c|}
\hline Kategori Throughput & Throughput & Indeks \\
\hline Bad & $0-338 \mathrm{kbps}$ & 0 \\
\hline Poor & $338-700 \mathrm{kbps}$ & 1 \\
\hline Fair & $700-1200 \mathrm{kbps}$ & 2 \\
\hline Good & $1200 \mathrm{kbps}-2.1 \mathrm{Mbps}$ & 3 \\
\hline 3) Jitter & $>2.1 \mathrm{Mbps}$ & 4 \\
\hline
\end{tabular}

Jitter adalah variasi atau perubahan latency dari delay atau variasi waktu kedatangan paket. Jitter juga didefinisikan sebagai gangguan pada komunikasi digital maupun analog yang disebabkan oleh perubahan sinyal karena referensi posisi 
DOI: https://doi.org/10.24843/MITE.2021.v20i01.P06

waktu. Adanya jitter ini dapat mengakibatkan hilangnya data, terutama pada pengiriman data dengan kecepatan tinggi. Berikut merupakan standar jitter menurut TIPHON [12]:

TABEL 2

STANDAR JITTER

\begin{tabular}{|c|c|c|}
\hline $\begin{array}{c}\text { Kategori } \\
\text { Jiter }\end{array}$ & Jitter & Indeks \\
\hline Poor & $125-255 \mathrm{~ms}$ & 1 \\
\hline Medium & $75-125 \mathrm{~ms}$ & 2 \\
\hline Good & $0-75 \mathrm{~ms}$ & 3 \\
\hline Perfect & $0 \mathrm{~ms}$ & 4 \\
\hline
\end{tabular}

\section{4) Packet Loss}

Packet loss adalah parameter yang menggambarkan suatu kondisi yang menunjukkan jumlah total paket yang hilang. Paket yang hilang ini dapat terjadi karena collision dan congestion pada jaringan.

Hal-hal yang mempengaruhi terjadinya packet loss, bisa karena kondisi geografis seperti kabut, hujan, gangguan radio frekuensi, sel handoff selama roaming, dan interferensi seperti pohon-pohon, bangunan, dan pegunungan. Packet loss dihitung berdasarkan persentase paket yang berhasil dikirim, dirumuskan sebagai berikut:

$$
\text { packet Loss: } \frac{\text { (Fachet Transwitted-Pachet Aleceived) }}{\text { Fachet Transmitted }} X 100
$$

Berikut adalah standar packet loss menurut TIPHON [12]:

TABEL 3

STANDAR PACKET LOSS

\begin{tabular}{|c|c|c|}
\hline $\begin{array}{c}\text { Kategori } \\
\text { Packet Loss }\end{array}$ & Packet Loss & Indeks \\
\hline Poor & $>25 \%$ & 1 \\
\hline Medium & $12-24 \%$ & 2 \\
\hline Good & $3-14 \%$ & 3 \\
\hline Perfect & $0-2 \%$ & 4 \\
\hline
\end{tabular}

\section{5) Latency}

Latency adalah total waktu tunda suatu paket yang diakibatkan oleh proses transmisi dari satu titik ke titik lain yang menjadi tujuannya. Berikut merupakan standar latency menurut TIPHON [12]:

TABEL 4

STANDAR LATENCY

\begin{tabular}{|c|c|c|}
\hline $\begin{array}{c}\text { Kategori } \\
\text { Latency }\end{array}$ & Latency & Indeks \\
\hline Poor & $>450 \mathrm{~s}$ & 1 \\
\hline Medium & $300-450 \mathrm{~s}$ & 2 \\
\hline Good & $150-300 \mathrm{~s}$ & 3 \\
\hline
\end{tabular}

Joshua Fernaldy Sudarsono: Rancang Bangun Alat Ukur...

\begin{tabular}{|l|l|l|}
\hline Perfect & $<150 \mathrm{~s}$ & 4 \\
\hline
\end{tabular}

\section{B. Raspberry Pi}

Raspberry Pi adalah komputer berukuran kecil yang dapat dihubungkan ke televisi atau monitor dan keyboard. Perangkat ini adalah komputer kecil yang mumpuni, dapat digunakan untuk proyek elektronik dan dapat melakukan banyak hal layaknya PC desktop atau komputer [13].

\section{Speedtest by Ookla}

Speedtest by Ookla adalah perangkat lunak (software) yang bertujuan untuk menguji kecepatan dan performa koneksi internet dengan parameter latency/jitter, download speed dan upload speed [14].

\section{METODE PENELITIAN}

\section{A. Tahapan Penelitian}

Alat Deteksi Kualitas Jaringan ini dibangun dengan menggunakan perangkat keras Raspberry Pi 3 Model B dan perangkat lunak Speedtest by Ookla. Adapun tahapan penelitian ini akan digambarkan melalui pseudocode melalui gambar 1 .

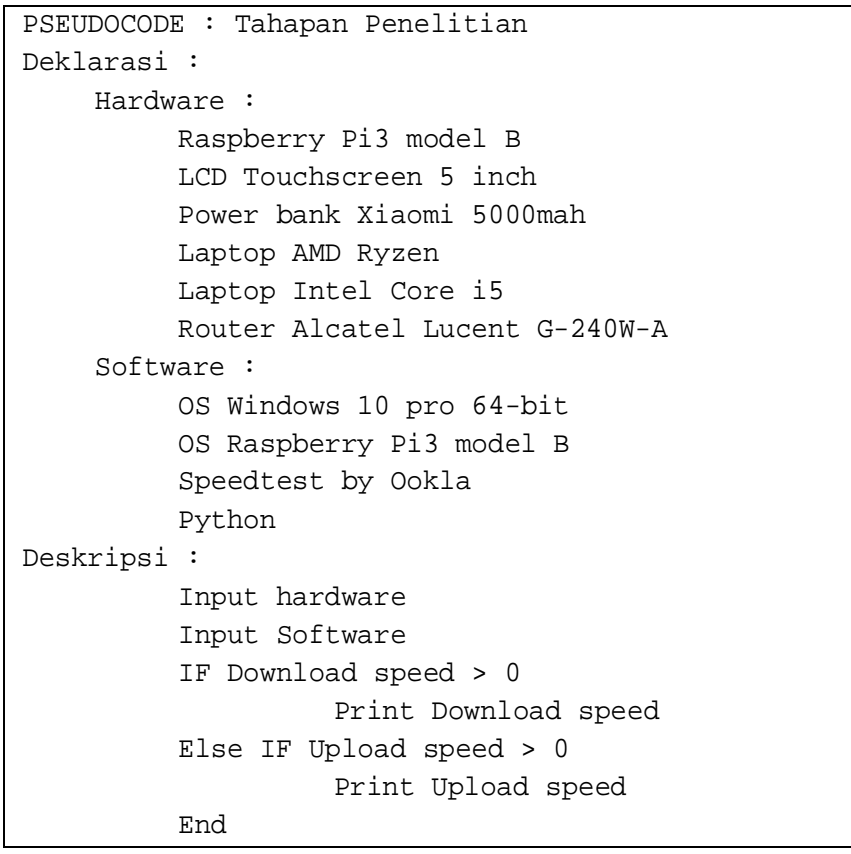

Gambar 1: Pseudocode Tahapan Penelitian

Berikut merupakan penjelasan dari tahapan penelitian yang digambarkan dalam pseudocode gambar 1 .

1. Tahapan dimulai dengan mengidentifikasi permasalahan yang ada di lingkungan masyarakat.

2. Melakukan diskusi dengan praktisi dan ahli mengenai perancangan alat deteksi kualitas jaringan.

3. Menyiapkan dan merancang peralatan termasuk Hardware dan Software. 
4. Melakukan pengujian dan perbandingan pada alat deteksi kualitas jaringan menggunakan algoritma pseudocode pada gambar 1 .

5. Menghubungkan alat dengan aplikasi Telegram dengan tujuan mempermudah penyimpanan hasil test.

6. Melakukan analisa dan membuat kesimpulan hasil penelitian.

\section{B. Rancang Bangun Perangkat Keras (Hardware)}

Perancangan atau desain dari perangkat keras (hardware) pada implementasi alat deteksi kualitas jaringan menggunakan Raspberry Pi 3 Model B yang akan dihubungkan dengan layar touchscreen berukuran 5 inch melalui GPIO dan connector HDMI. Untuk sumber tegangan, alat ini menggunakan powerbank berukuran $5000 \mathrm{mAh}$ dengan konektor kabel USB type A to micro USB.

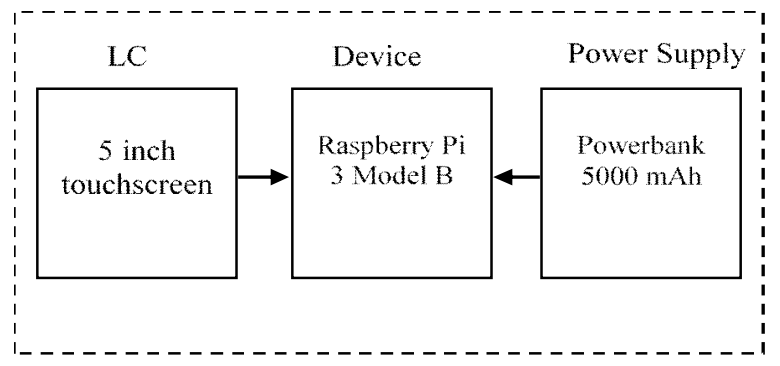

Gambar 2: Diagram Alir Perancangan Perangkat Keras

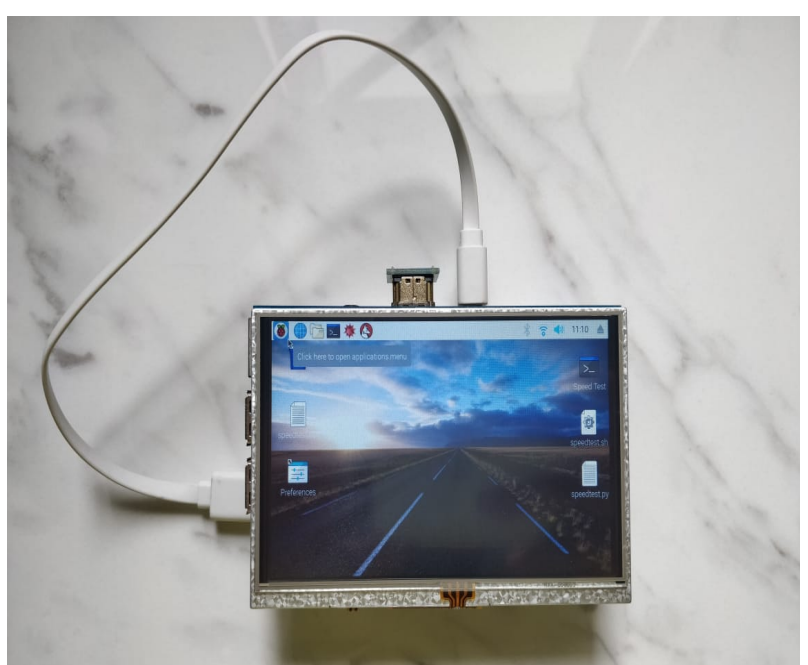

Gambar 3: Prototype Alat Ukur Kualitas Jaringan

\section{Rancang Bangun Perangkat Lunak (Software)}

Perancangan atau desain dari perangkat lunak (software) pada implementasi alat deteksi kualitas jaringan meliputi proses pengukuran kualitas jaringan dan mengirimkan hasil uji melalui telegram. Software terdiri dari 4 bagian, dimana speedtest cli merupakan software dasar dan dilanjutkan dengan speedtest.py, speedtest.desktop, dan speedtest.sh. Tahapan Perancangan software dijelaskan melalui diagram berikut.

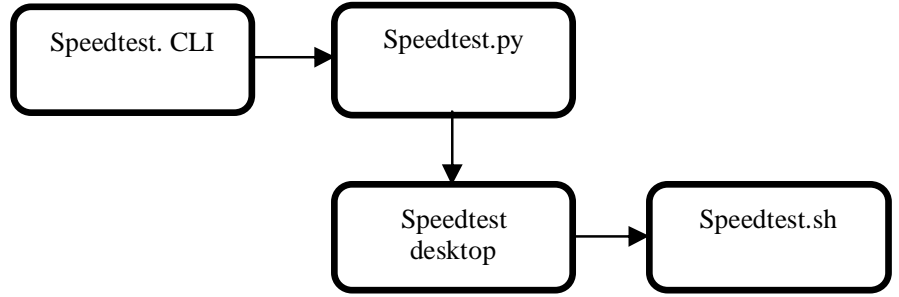

Gambar 4: Diagram Blok Perancangan Software

Urutan eksekusi pada program pengujian ini dapat dijelaskan melalui diagram pada gambar 5

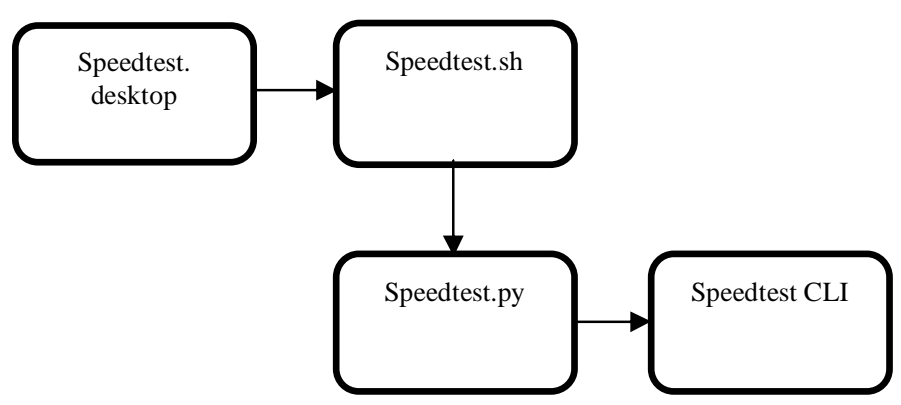

Gambar 5: Diagram blok urutan eksekusi software

Pada urutan eksekusi software dapat dilihat bahwa Speedtest.desktop sebagai shortcut menjalankan Speedtest.sh (shell) yang akan menjalankan Speedtest.py, dan speedtest.py akan menjalankan Speedtest CLI dengan perubahan tampilan sesuai dengan yang sudah diatur pada Speedtest.py.

\section{1) Pemasangan Software Speedtest CLI}

Speedtest.cli merupakan program dasar yang digunakan pada pengujian. Speedtest.cli diinstall dengan menggunakan command yang dijalankan melalui terminal atau command prompt. Berikut merupakan algoritma yang digunakan untuk menginstal program speedtest CLI.

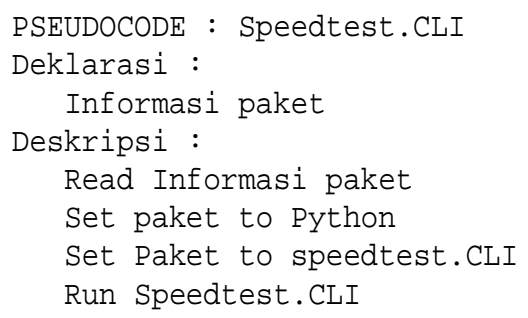

Gambar 6: Algoritma Speedtest.CLI

\section{2) Pembuatan Speedtest.py}

Speedtest.py dibuat menggunakan bahasa pemrograman python. Berikut adalah algoritma program Speedtest.py. 


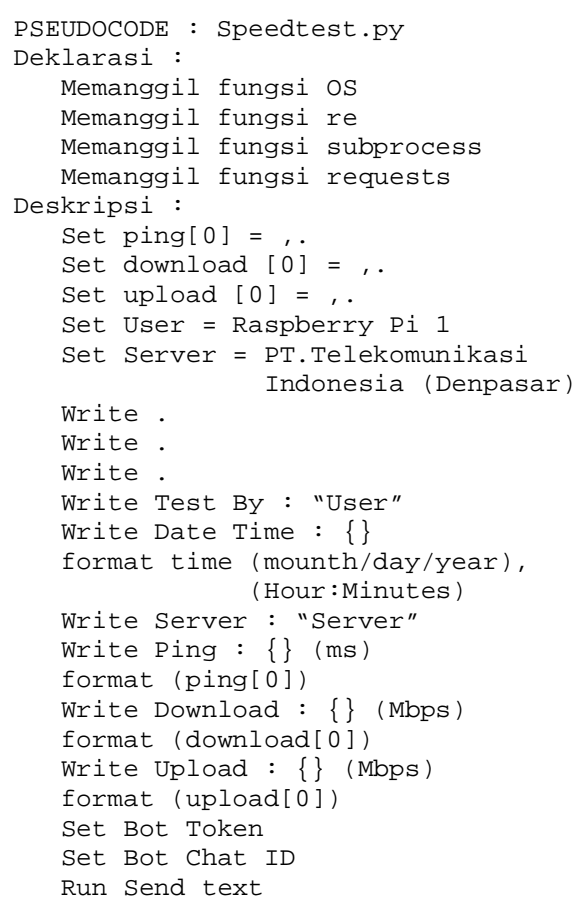

Gambar 7: Algoritma Speedtest.py

3) Pembuatan Speedtest.desktop dan shell

Joshua Fernaldy Sudarsono: Rancang Bangun Alat Ukur...
Speedtest.desktop adalah command yang digunakan untuk menjalankan shell (speedtest.sh) dan shell akan menjalankan program Speedtest.py. Berikut merupakan algoritma speedtest.desktop dan shell.

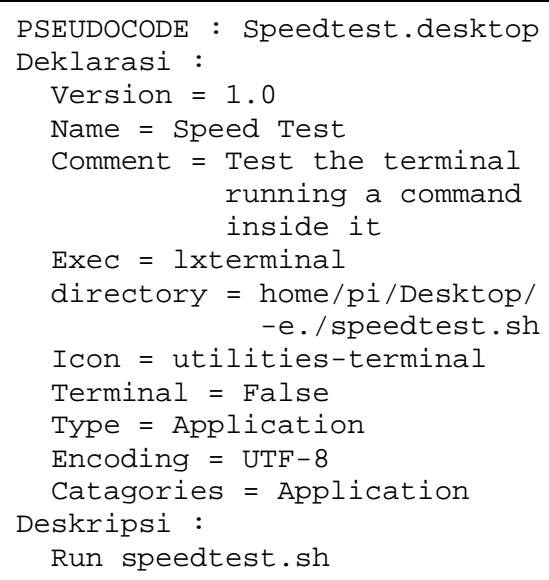

Gambar 8: Algoritma Speedtest.desktop

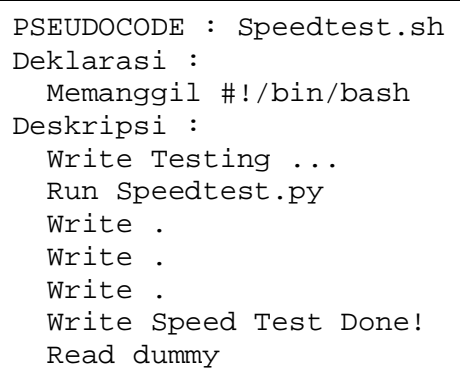

Gambar 9: Algoritma speedtest.sh

\section{Diagram Blok Pengujian}

Pada penelitian ini dilakukan dua macam pengujian yaitu pengujian performa dan daya tahan battery.

Pengujian performa bertujuan untuk mengetahui apakah kemampuan alat uji layak digunakan sebagai alternatif pengganti dari fungsi laptop. Pengujian akan dilakukan 
dengan menjalankan software Speedtest by Ookla pada semua perangkat uji dengan 2 media transmisi yaitu kabel dan nirkabel

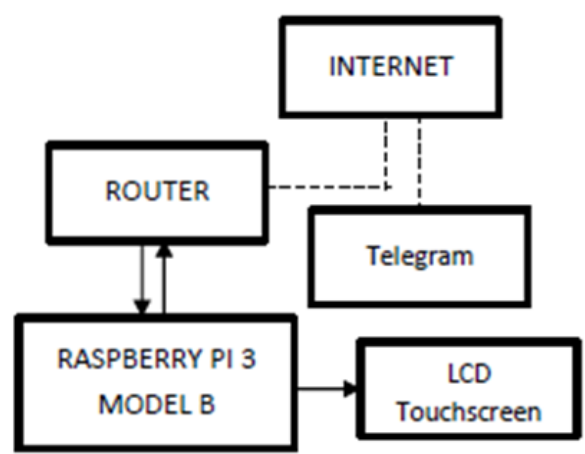

Gambar 10: Diagram Blok Pengujian Performa Media Transmisi Kabel

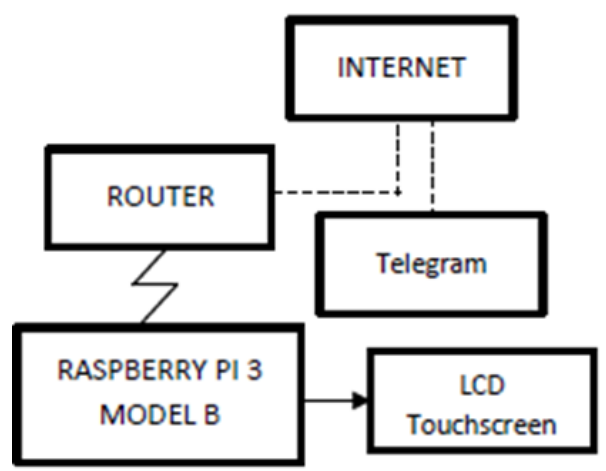

Gambar 11: Diagram Blok Pengujian Performa Media Transmisi Nirkabel

Gambar 10 menunjukkan diagram blok pengujian performa dengan media transmisi kabel dimana Raspberry Pi yang sudah terhubung dengan router melalui kabel melakukan pengujian performa dengan parameter ping, download rate, dan upload rate. Hasil pengujian akan ditampilkan pada layar dan akan dikirmkan ke media sosial telegram melalui internet. Pada gambar 11 dapat dilihat bahwa dilakukan pengujian yang sama namun Raspberry Pi terhubung dengan router melalui media transmisi nirkabel.

Pengujian daya tahan battery bertujuan untuk mengetahui apakah secara life-time alat uji ini layak untuk menjadi alternatif pengganti dari fungsi laptop. Pengujian dilakukan dengan mengukur life-time perangkat dari kondisi battery 100\%-0\% dengan mode idle dan running video. Data hasil berupa waktu dan akan diukur menggunakan stopwatch.

\section{HASIL DAN PEMBAHASAN}

Merancang prototype alat yang dapat menggantikan fungsi laptop sebagai alat uji layanan dengan lebih praktis, ekonomis serta performa yang memadai.

\section{A. Analisis Data Pengujian Performa}

Pengujian performa dilakukan dengan menjalankan program Speedtest by Ookla dan menguji perangkat melalui parameter ping, download rate dan upload rate. Berikut merupakan perbandingan hasil pengujian.

TABEL 5

Perbandingan Hasil Pengujian Ping Menggunakan Media Transmis KABEL

\begin{tabular}{|c|c|c|}
\hline Raspberry Pi & Laptop 1 & Laptop 2 \\
\hline $50.93 \mathrm{~ms}$ & $2 \mathrm{~ms}$ & $4 \mathrm{~ms}$ \\
\hline $20.48 \mathrm{~ms}$ & $3 \mathrm{~ms}$ & $5 \mathrm{~ms}$ \\
\hline $19.50 \mathrm{~ms}$ & $3 \mathrm{~ms}$ & $4 \mathrm{~ms}$ \\
\hline $23.56 \mathrm{~ms}$ & $3 \mathrm{~ms}$ & $4 \mathrm{~ms}$ \\
\hline $22.62 \mathrm{~ms}$ & $2 \mathrm{~ms}$ & $3 \mathrm{~ms}$ \\
\hline
\end{tabular}

Pada tabel 5 menunjukan data hasil pengujian delay atau ping pada setiap perangkat menggunakan transmisi kabel. Perangkat Raspberry Pi menunjukan angka $19-50 \mathrm{~ms}$, sedangkan laptop 1 menunjukan angka 2-3 ms, dan laptop 2 menunjukan angka 3-5 ms.

TABEL 6

Perbandingan Hasil Pengujian Ping Menggunakan Media Transmisi NIRKABEL

\begin{tabular}{|c|c|c|}
\hline Raspberry Pi & Laptop 1 & Laptop 2 \\
\hline $22.95 \mathrm{~ms}$ & $3 \mathrm{~ms}$ & $4 \mathrm{~ms}$ \\
\hline $21.65 \mathrm{~ms}$ & $4 \mathrm{~ms}$ & $4 \mathrm{~ms}$ \\
\hline $25.15 \mathrm{~ms}$ & $3 \mathrm{~ms}$ & $4 \mathrm{~ms}$ \\
\hline $27.70 \mathrm{~ms}$ & $3 \mathrm{~ms}$ & $4 \mathrm{~ms}$ \\
\hline $24.53 \mathrm{~ms}$ & $4 \mathrm{~ms}$ & $4 \mathrm{~ms}$ \\
\hline
\end{tabular}

Pada tabel 6 menujukan data hasil pengujian delay atau ping pada setiap perangkat dengan transmisi nirkabel. Perangkat Raspberry Pi menunjukan angka 21-27 ms, sedangkan laptop 1 menunjukan angka 3-4 ms, dan laptop 2 menunjukan angka yang stabil di $4 \mathrm{~ms}$.

TABEL 7

Perbandingan Hasil Pengujian Ping TANPa Koneksi Internet

\begin{tabular}{|c|c|c|}
\hline Raspberry Pi & Laptop 1 & Laptop 2 \\
\hline$-\mathrm{ms}$ & $-\mathrm{ms}$ & $-\mathrm{ms}$ \\
\hline$-\mathrm{ms}$ & $-\mathrm{ms}$ & $-\mathrm{ms}$ \\
\hline
\end{tabular}

Pada Tabel 7 menunjukan data hasil pengujian delay atau ping setiap perangkat tanpa terhubung ke internet. Semua perangkat jelas tidak dapat menunjukan nilai angka.

Secara keseluruhan dapat dilihat bahwa Raspberry Pi mendapatkan hasil pengukuran yang lebih besar dari pada laptop 1 dan 2, namun masih dalam kategori baik menurut Jolene Dobbin yang dimuat dalam situs web [15]. Hal ini terjadi karena perbedaan performa processor antara Raspberry $\mathrm{Pi}$, laptop 1 dan laptop 2. Dimana Raspberry Pi model 3 menggunakan processor BCM2837 Cortex-A53 1.2GHz, sedangkan laptop 1 dan 2 masing-masing menggunakan processor AMD Ryzen $7-3750 \mathrm{H} 2.3 \mathrm{GHz}$, dan Intel core i5$4200 \mathrm{U} 1.6 \mathrm{GHz}$ [16]-[18]. 
TABEL 8

PERbandingan Hasil PENGUJian Download dAN Upload Rate MENGGUNAKAN MEDIA TRANSMISI KABEL

\begin{tabular}{|c|c|c|c|c|c|}
\hline \multicolumn{2}{|c|}{ Raspberry Pi } & \multicolumn{2}{c|}{ Laptop 1 } & \multicolumn{2}{c|}{ Laptop 2 } \\
\hline Download & Upload & Download & Upload & Download & Upload \\
\hline 14.10 & 1.41 & 14.27 & 1.43 & 14.51 & 1.40 \\
Mbps & Mbps & Mbps & Mbps & Mbps & Mbps \\
\hline 13.95 & 1.65 & 14.46 & 1.41 & 14.06 & 1.44 \\
Mbps & Mbps & Mbps & Mbps & Mbps & Mbps \\
\hline 14.12 & 1.45 & 14.52 & 1.44 & 14.47 & 1.44 \\
Mbps & Mbps & Mbps & Mbps & Mbps & Mbps \\
\hline 14.09 & 1.45 & 14.51 & 1.45 & 14.50 & 1.44 \\
Mbps & Mbps & Mbps & Mbps & Mbps & Mbps \\
\hline 14.00 & 2.03 & 14.54 & 1.40 & 14.51 & 1.45 \\
Mbps & Mbps & Mbps & Mbps & Mbps & Mbps \\
\hline
\end{tabular}

Pada tabel 8 menunjukan hasil pengujian kecepatan download dan upload pada setiap perangkat menggunakan transmisi kabel. Kecepatan download pada perangkat Raspberry Pi menunjukan angka 13-14 Mbps, sedangkan laptop 1 dan 2 stabil di 14 Mbps. Kecepatan upload pada perangkat Raspberry $\mathrm{Pi}$ menunjukan angka 1-2 Mbps, sedangkan laptop 1 dan 2 stabil di 1 Mbps.

TABEL 9

PERbandingan Hasil PenguJian DownLOAd DAN Upload RATE MENGGUNAKAN MEDIA TRANSMISI NIRKABEL

\begin{tabular}{|c|c|c|c|c|c|}
\hline \multicolumn{2}{|c|}{ Raspberry Pi } & \multicolumn{2}{c|}{ Laptop 1 } & \multicolumn{2}{c|}{ Laptop 2 } \\
\hline Download & Upload & Download & Upload & Download & Upload \\
\hline 13.88 & 2.09 & 14.52 & 1.16 & 14.49 & 0.99 \\
Mbps & Mbps & Mbps & Mbps & Mbps & Mbps \\
\hline 14.01 & 1.67 & 14.55 & 1.30 & 14.49 & 1.03 \\
Mbps & Mbps & Mbps & Mbps & Mbps & Mbps \\
\hline 13.36 & 1.63 & 14.05 & 1.09 & 14.09 & 1.34 \\
Mbps & Mbps & Mbps & Mbps & Mbps & Mbps \\
\hline 13.05 & 1.74 & 13.83 & 1.42 & 14.03 & 0.86 \\
Mbps & Mbps & Mbps & Mbps & Mbps & Mbps \\
\hline 13.65 & 1.49 & 14.49 & 1.16 & 13.57 & 1.19 \\
Mbps & Mbps & Mbps & Mbps & Mbps & Mbps \\
\hline
\end{tabular}

Pada tabel 9 menunjukan hasil pengujian kecepatan download dan upload pada setiap perangkat menggunakan transmisi nirkabel. Pada kecepatan download semua perangkat menunjukan angka 13-14 Mbps. Pada kecepatan upload perangkat Rasspberry $\mathrm{Pi}$ menunjukan angka 1-2 Mbps, sedangkan Laptop 1 stabil di angka 1 Mbps, dan laptop 2 menunjukan angka 0-1 Mbps.

TABEL 10

Perbandingan Hasil Pengujian Download dan Upload Rate TanPa KONEKSI INTERNET

\begin{tabular}{|c|c|c|c|c|c|}
\hline \multicolumn{2}{|c|}{ Raspberry Pi } & \multicolumn{2}{c|}{ Laptop 1 } & \multicolumn{2}{c|}{ Laptop 2 } \\
\hline Download & Upload & Download & Upload & Download & Upload \\
\hline- Mbps & - Mbps & - Mbps & - Mbps & - Mbps & - Mbps \\
\hline- Mbps & - Mbps & - Mbps & - Mbps & - Mbps & - Mbps \\
\hline
\end{tabular}

Joshua Fernaldy Sudarsono: Rancang Bangun Alat Ukur...
Pada tabel 10 menunjukan hasil pengujian kecepatan download dan upload pada setiap perangkat tanpa

menggunakan koneksi internet, hasilnya jelas tidak menunjukan nilai angka.

Secara keseluruhan dapat dilihat bahwa data hasil pengukuran download dan upload rate pada Raspberry Pi hampir sama dengan data hasil laptop 1 dan laptop 2. Sedikit perbedaan kecepatan internet terjadi karena kondisi internet yang dinamis dan terjadi jeda beberapa milisekon pada saat memulai pengukuran antar perangkat, jadi penulis tidak dapat menjamin $100 \%$ kesamaan waktu mulai pengujian pada setiap perangkat yang digunakan.

\section{B. Analisis Pengujian Daya Tahan Battery}

Pengujian ini bertujuan untuk mengetahui daya tahan battery perangkat guna mendukung pekerjaan di lapangan. Pengujian dilakukan dengan cara menghitung lamanya waktu hidup perangkat dari kondisi battery $100 \%$ hingga $0 \%$ dengan kondisi idle dan running video. Berikut merupakan data hasil pengujian daya tahan battery.

TABEL 11

PERBANDINGAN HASIL DAYA TAHAN BATTERY MODE IDLE

\begin{tabular}{|c|c|c|}
\hline Raspberry Pi & Laptop 1 & Laptop 2 \\
\hline 5 jam 25 menit & 7 jam 8 menit & 5 jam 42 menit \\
\hline 5 jam 37 menit & 7 jam 2 menit & 5 jam 51 menit \\
\hline 5 jam 33 menit & 7 jam 6 menit & 5 jam 42 menit \\
\hline
\end{tabular}

Pada tabel 11 dapat dililhat bahwa laptop 1 mendapatkan hasil lifetime tertinggi, dan Raspberry $\mathrm{Pi}$ mendapatkan lifetime yang hampir sama dengan laptop 2 .

TABEL 12

PERBANDINGAN HASIL DAYA TAHAN BATTERY MODE RUNNING VideO

\begin{tabular}{|c|c|c|}
\hline Raspberry Pi & Laptop 1 & Laptop 2 \\
\hline 4 jam 10 menit & 6 jam 16 menit & 2 jam 39 menit \\
\hline 4 jam 9 menit & 6 jam 16 menit & 2 jam 36 menit \\
\hline
\end{tabular}

Pada table 12 mode running video Raspberry $\mathrm{Pi}$ mendapatkan hasil yang lebih baik dari laptop 2. Hal ini terjadi karena Raspberry Pi menggunakan Powerbank Xiaomi dengan kapsitas 25Wh sebagai supply daya. Sedangkan laptop 1 dan laptop 2 masing-masing memiliki baterai sebesar 76Wh, dan 41Wh sebagai supply daya [17], [18].

\section{Perbandingan Harga Perangkat}

Perbandingan harga perangkat dilakukan untuk mengetahui total harga yang dibutuhkan pada setiap perangkat guna mengetahui perangkat yang dinilai lebih ekonomis. Secara keseluruhan total harga yang dibutuhkan untuk membuat sebuah alat uji sebesar Rp. 1.120.000, sedangkan untuk laptop 1 membutuhkan biaya sebesar Rp.15.999.000,dan laptop 2 sebesar Rp. 7.890.000, sehingga apabila dilihat dari keseluruhan harga dapat disimpulkan bahwa Raspberry Pi dinilai lebih ekonomis dari pada laptop 1 dan laptop 2 [19], [20]. 


\section{KESIMPULAN}

Berdasarkan pembahasan dan perbandingan hasil pengujian antara alat ukur kualitas jaringan berbasis Raspberry pi 3 model B dengan perangkat berbasis Laptop didapatkan kesimpulan sebagai berikut:

1. Hasil uji performa dengan parameter ping pada Raspberry Pi mendapatkan hasil hasil yang lebih tinggi namun hasil ping tersebut masih dalam batas toleransi sesuai standar yang ada. Sedangkan, pengujian parameter download rate dan upload rate, kedua perangkat memberikan hasil yang hampir sama.

2. Pengujian daya tahan battery pada mode idle, perangkat Raspberry $\mathrm{Pi}$ dan laptop 2 memiliki daya tahan yang hampir sama yaitu 5 jam. Sedangkan, pengujian dengan mode running video menghasilkan perangkat berbasis Raspberry memiliki ketahanan lebih tinggi dibandingkan laptop 2 yaitu dengan perbandingan 4 jam dengan 2 jam.

3. Total biaya yang dikeluarkan untuk membuat alat ukur kualitas jaringan dengan Raspberry Pi 3 Model B dinilai lebih ekonomis dari pada biaya untuk sebuah laptop.

\section{UCAPAN TERIMA KASIH}

Terima kasih diperuntukan kepada bapak Haris Setiawan selaku donatur perangkat Raspberry Pi model 3 beserta LCD, sehingga penelitian ini dapat dilaksanakan dan selesai dengan seksama.

\section{REFERENSI}

[1] (2018) Dewaweb. Pengertian Internet. [Online]. Available: https://www.dewaweb.com/blog/pengertian-internet/amp/

[2] D. H. Jayani, (2019) Berapa Pengguna Internet di Indonesia. [Online] Available:

https://databoks.katadata.co.id/datapublish/2019/09/09/berapapengguna-internet-di-indonesia

[3] Jonathan, Pradana, Hermawan, Didit. Network Traffic Management, Quality of Service (QoS), Congestion Control dan Frame Relay. Universitas Gunadarma. 2011.

[4] A. G. Nasution, "Perancangan Jaringan Fiber to the Home (Ftth) Dengan Teknologi Gigabit Passive Optical Network (Gpon) (Studi Kasus Di Daerah Turangga Bandung)," vol. 11, no. 1995, pp. $2011-$ 2013. 2015.

[5] Safitri, Dhian, dkk. Analisis Kualitas Jaringan Akses Indihome Untuk Teknologi GPON dan MSAN di STO Darussalam. Karya Ilmiah Teknik Elektro, Vol 1(3), Pg. 27-34. 2016.

[6] Haryanto, dan, S. Nandiroh. Kualitas Jaringan Komunikasi Sektor Industri dengan Inteligent Network sebagai Upaya Perluasan Daerah Pemasaran, Vol 4(1), Pg. 34-40. 2005.

[7] Wulandari, Rika. Analisis QoS (Quality of Service) pada Jaringan Internet (Studi Kasus: UPT Loka Uji Teknik Penambangan Jampang Kulon - LIPI). Jurnal Teknik Informatika dan Sistem Informasi, Vol 2(2), Pg. 162-172. 2016.

[8] E. N. Wijatsongko, A. E. Putra, \& B. N. Prastowo. Sistem Pemantauan Ruangan Dengan Server Raspberry Pi. IJEIS (Indonesian Journal of Electronics and Instrumentation Systems), Vol 5(1), Pg. 65-76. 2015.

[9] K.K.A. Subrata, I.M.O. Widyantara, Linawati. Klasifikasi Penggunaan Protokol Komunikasi Pada Trafik Jaringan Menggunakan Algoritma K-Nearest Neighbor. Majalah Ilmiah Teknologi Elektro, [S.1.], v. 16, n. 1, p. 67-74, july 2016. ISSN 2503-2372.

[10] I M.O. Widyantara, B.D. Cahyono, W. Setiawan. Analisa Horizontal Handover Terhadap Qos Layanan Streaming Multimedia E-Learning Pada Jaringan WLAN 802.11. Majalah Ilmiah Teknologi Elektro, [S.1.], v. 14, n. 1, june 2015. ISSN 2503-2372.

[11] I N. Bernadus, N. Gunantara, K.O. Saputra. Analisis Kinerja Jaringan Internet dengan Metode Class Based Queueing di Universitas Dhyana Pura. Majalah Ilmiah Teknologi Elektro, [S.1.], v. 18, n. 1, p. 133-140, may 2019. ISSN 2503-2372.
[12] M. Riadi, (2019) Pengertian, Layanan dan Parameter Quality of Service. [Online]. Available: https://www.kajianpustaka.com/2019/05/pengertian-layanan-danparameter-quality-of-service-qos.html

[13] D. K. Salim, J. Andjawirawan, and L. P. Dewi, Penerapan Screen Mirroring Android pada Projector Menggunakan Raspberry Pi., 2019.

[14] (2006) Ookla. [Online]. Available: https://www.speedtest.net/about (accessed Feb. 22, 2020).

[15] J. Dobbin, (2020) Lag! Top 5 Reasons your Ping is so High. [Online]. Available https://store.hp.com/us/en/tech-takes/5-reasons-your-ping-isso-high\#: :text=Ping amounts of $100 \mathrm{~ms}$,and deemed "high ping."

[16] (2020) Digiware Store. Perbandingan Spesifikasi Raspberry Pi 4/3B+/3B/2B/1B+/1 A+. [Online]. Available: https://digiwarestore.com/id/digiware-news/50_perbandinganspesifikasi-raspberry-pi

[17] H. M. Nugraha, (2020) Review Asus ROG Zephyrus G GA 502. [Online]. Available: https://rog.asus.com/id/laptops/rog-zephyrus/rogzephyrus-g15-series/spec/

[18] (2019) Laptophia. HP 14s-CF1028TX. [Online]. Available: https://www.laptophia.com/2019/05/hp-14scf1028tx-laptop-kekinian2019.html

[19] (2020) Tokopedia. Asus ROG Zephyrus G GA502DU Ryzen7 3750 8GB 512ssd TX1660Ti 6GB W10. [Online]. Available: https://www.tokopedia.com/janurtech/asus-rog-zephyrus-g-ga502duryzen7-3750-8gb-512ssd-tx1660ti-6gb-w10?whid=0

[20] (2020) Tokopedia. Hp Notebook 14s-cf1028tx 5qh32pa - Silver. [Online]. Available: https://www.tokopedia.com/jakartahand/hpnotebook-14s-cf1028tx-5qh32pa-silver?whid=0 